\title{
Influence of leisure activity on the incidence of Alzheimer's Disease
}

\author{
N. Scarmeas, MD; G. Levy, MD; M.-X. Tang, PhD; J. Manly, PhD; and Y. Stern, PhD
}

\begin{abstract}
Article abstract-Objective: To determine whether leisure activities modify the risk for incident dementia. Background: Although high educational and occupational attainments have been associated with reduced risk of incident dementia, the relation between leisure activities and dementia risk has not been adequately investigated. Methods: A total of 1,772 nondemented individuals aged 65 years or older, living in northern Manhattan, New York, were identified and followed longitudinally in a community-based cohort incidence study. Subjects' leisure activities at baseline were assessed, annual examinations with the same standardized neurologic and neuropsychological measures were performed for up to 7 years (mean 2.9 years), and incident dementia was assessed as the main outcome measure. Cox proportional hazards models, adjusting for age, ethnic group, education, and occupation, were used to estimate the relative risk (RR) of incident dementia associated with high leisure activities. Results: Of the 1,772 subjects, 207 became demented. The risk of dementia was decreased in subjects with high leisure activities (RR, 0.62; 95\% CI 0.46 to 0.83 ). The association of high leisure with decreased $\mathrm{RR}$ of incident dementia was present even when baseline cognitive performance, health limitations interfering with desired leisure activities, cerebrovascular disease, and depression were considered. Conclusions: The data suggest that engagement in leisure activities may reduce the risk of incident dementia, possibly by providing a reserve that delays the onset of clinical manifestations of the disease.
\end{abstract}

NEUROLOGY 2001;57:2236-2242

Both prevalence and incidence of $\mathrm{AD}$ seem to be higher in individuals with fewer years of education and lower occupational attainment. ${ }^{1-6}$ There are several possible explanations for these findings. Low educational level or occupational status might influence a causal factor, ${ }^{7}$ or might contribute to poorer performance on neuropsychometric tests used to diagnose dementia. ${ }^{8}$ Alternatively, it has been hypothesized that these factors provide protection or reserve against the manifestation of the disease. ${ }^{9-13}$

Factors other than education and occupation might also provide reserve and influence the incidence of $\mathrm{AD}$. There have been only two prospective longitudinal studies evaluating the relation of engagement in intellectual, social, or leisure activities to incident dementia. The first one was negative ${ }^{14}$ and the other showed a protective effect only for some specific activities (traveling, doing odd jobs, and knitting). ${ }^{15}$

The present analyses were designed to clarify the role of leisure activities in a prospective study of incident dementia. We hypothesized that leisure activities contribute to the reserve against dementia by preserving a set of skills or repertoires that allow the individual to cope longer before the clinical manifestations of $\mathrm{AD}$ emerge. Because the nature of recreational and social activities on the incidence of the disease per se may be related to the individual's educational and occupational attainment, our analyses adjusted for education and occupation. Since we had previously shown a decreased relative risk (RR) of dementia in patients with higher educational and occupational attainment, ${ }^{13}$ the present analyses asked whether increased leisure activities were associated with decreased risk over and above that associated with these other markers of cognitive reserve.

Methods. Subjects. The cohort was identified from a probability sample of Medicare beneficiaries residing in an area of three contiguous census tracts in the northern Manhattan communities of Washington Heights and Inwood in New York City, an area from 151st Street north to 181st Street and bounded by the Hudson and Harlem rivers. Access to the names of individuals was provided by the Health Care Financing Administration (HCFA). Prior to recruitment, each individual was send a joint letter explaining that they had been selected to participate in a study of aging by investigators at Columbia University. The original HCFA list of 5,403 names was then divided into six strata based on ethnic group and age (65 to 74 years, and 75 years and older). We used HCFA data, supplemented by 1990 United States Census files that included a Hispanic surname list, to categorize ethnic group. These strata were further subdivided into 37 representative subsamples so that the distributions by ethnic group

From the Cognitive Neuroscience Division of the Gertrude H. Sergievsky Center (Drs. Levy, Tang, Manly, and Stern), the Department of Neurology (Drs. Scarmeas, Manly, and Stern) and Psychiatry (Dr. Stern), the Taub Institute for Research in Alzheimer's Disease and the Aging Brain (Drs. Scarmeas, Tang, and Stern), and the Division of Biostatistics (Dr. Tang) in the School of Public Health, Columbia University College of Physicians and Surgeons, New York, NY.

Supported by federal grants AG07232, RR00645, and the Taub Institute for Research in Alzheimer's Disease and the Aging Brain.

Received May 7, 2001. Accepted in final form September 10, 2001.

Address correspondence and reprint requests to Yaakov Stern, Gertrude H. Sergievsky Center, 630 West 168th Street, New York, NY, 10032; e-mail: ys11@columbia.edu 
and age within each subsample would be similar. This provided the means to ensure equal representation of the community during the initial assessment of participants.

We determined that $896(16.6 \%)$ of the 5,403 no longer lived in the region, and $470(8.7 \%)$ were dead. Another 409 $(7.6 \%)$ could not be located despite numerous attempts to contact them by telephone, regular mail, and letters dropped off at the address provided by HCFA. The proportion of individuals within each age stratum not located or found to be deceased was similar across the three ethnic groups. An additional 176 (3.3\%) were either ineligible (below age 65 years), did not reside in the community during the baseline study period, or spoke languages other than English or Spanish. In addition, 1,324 (25\%) refused to participate. Excluding those who died, the proportion of individuals in each age stratum who did not wish to participate for any reason, including refusal, did not differ by ethnic group. Two individuals were duplicated in the database under different names. Data from 2,126 (62\%) of the 3,452 eligible were included in the baseline assessment. Based on the distributions within the 37 subsamples, the proportion of individuals within each ethnic group and age stratum who participated in the study did not differ significantly from the source population.

The Columbia University institutional review board reviewed and approved this project. All subjects provided written informed consent.

Subjects included in the current analyses met the following criteria: 1) They were nondemented at the baseline diagnostic evaluation (described below); 2) they had not had an acute stroke or PD in the year prior to their initial visit; and 3) they were seen for at least one follow-up evaluation.

Diagnostic evaluation. At the baseline interview, ethnic group was confirmed by self-report using the format of the 1990 United States Census. Briefly, each individual was first asked to indicate his racial group, then asked whether or not he was of "Hispanic" origin. Mixed category was not a category in the 1990 Census. This again confirmed the separation into three groups: Black (AfricanAmerican, non-Hispanic), White (non-Hispanic), or Hispanic. Hispanics could therefore be either Black or White. For Hispanics, we also asked their country of birth or origin.

Subjects were evaluated over a 7-year study period. Evaluations were conducted in English or Spanish, based on the subjects' primary language and their opinion of which language would yield better performance. The maximum number of assessments was four (baseline and three follow-ups). Individuals in the first four subsamples (12\% of the cohort) underwent a detailed general health interview that included a cognitive test, the Care-Diagnostic Interview, ${ }^{16}$ and an assessment of the ability to perform activities of daily life. A standardized medical, neurologic, and neuropsychological examination (described below) was also completed. ${ }^{17}$ In the remaining 33 subsamples, we used a two-stage procedure. Based on the results from the first four subsamples, we determined that the probability of dementia among individuals with a Care-Diagnostic Interview score below 3 was $6 \%$. Therefore, only those subjects with a Care-Diagnostic Interview score of 3 or higher, and $25 \%$ random sample of those with scores below 3 underwent the detailed examination described above in the first four subsamples $(\mathrm{N}=1,072,50.4 \%)$. However, for all follow-up assessments, every subject, regardless of the Care-Diagnostic Interview score, received the complete clinical examination described below.

A physician elicited each subject's medical and neurologic history and conducted a standardized physical and neurologic examination. All ancillary information (medical charts, CT, or MRI) was considered in the evaluation, if available. The presence of a history or signs or symptoms of stroke, as well as the presence of diabetes, hypertension, or other medical conditions and smoking were noted. Prescribed medications were reviewed and recorded. Medical diagnoses were assigned when applicable. This examination was repeated at each follow-up.

The neuropsychological battery ${ }^{17}$ took approximately 1 hour to complete and contained tests of memory (shortand long-term verbal ${ }^{18}$ and nonverbal ${ }^{19}$ ); orientation; abstract reasoning (verbal ${ }^{20}$ and nonverbal ${ }^{21}$ ); language (naming, ${ }^{22}$ verbal fluency, ${ }^{23,24}$ comprehension, ${ }^{24}$ and repetition $^{24}$ ); and construction (copying ${ }^{25}$ and matching ${ }^{19}$ ). Test scores were evaluated using a fixed paradigm ${ }^{17}$ : criterion scores were applied to each test score, and subjects performing below these scores on two of the three aspects of memory testing as well as two other areas (orientation, language, abstract reasoning, or construction) were considered to have sufficient cognitive deficit to meet criteria for dementia. In addition, the short version of the Blessed Memory Information and Concentration Test ${ }^{26}$ as well as the Blessed Dementia Rating Scale (part I, sections A and B ${ }^{27}$ and the Schwab and England Activities of Daily Living Scale ${ }^{28}$ were administered to a subset of patients during the first evaluation only. Screening items for depression, psychosis, and alcohol abuse (Structured Clinical Interview for Diagnostic and Statistical Manual of Mental Disorders, Third Edition, Revised [DSM-III-R] Diagnosis [SCID] screen $^{29}$ ) were also administered. Finally, the Hamilton Depression Rating Scale ${ }^{30,31}$ was administered to a subset of subjects.

A consensus diagnosis for the presence or absence of dementia was made at a diagnostic conference of physicians and neuropsychologists where information of all the above evaluations was presented. Evidence of cognitive deficit, based on the neuropsychological scores, and evidence of impairment in social or occupational function, as assessed by the Blessed Dementia Rating Scale and the Swab and England Activities of Daily Living Scale were the criteria used for the diagnosis of dementia as required by the DSM-III-R. ${ }^{32}$

The type of dementia was subsequently determined. For the diagnosis of probable or possible $\mathrm{AD}$, the criteria of the National Institute of Neurologic and Communicative Disorders and Stroke-Alzheimer's Disease and Related Disorders Association ${ }^{33}$ (NINCDS/ADRDA) were used. Either a history or clinical evidence of stroke or a lesion noted on MRI prompted a diagnosis of either possible $\mathrm{AD}$ with concomitant stroke or stroke-related dementia. The latter was diagnosed only when there appeared to be a clear temporal relation between vascular events and the onset of dementia (operationally defined as onset of dementia within 3 months of the stroke). In addition, a modified Clinical Dementia Rating (CDR) $)^{34}$ was assigned to each subject. Demented patients were assigned a CDR of 1 or more, and not demented a CDR of zero, according to the published 
criteria. CDR of 0.5 was assigned to subjects who did not have sufficient cognitive deficit to meet criteria for dementia according to the fixed paradigm, but whose test performance fell below many of the paradigm's criterion scores and had evidence of mild functional impairment.

Neurologists who examined the subjects, but not the neuropsychological testers, were members of the diagnostic conference panel. The members of the panel were usually aware of the educational, but not the occupational, attainment or degree of leisure activities of the subjects. The knowledge of education did not influence diagnosis of dementia because the fixed diagnostic paradigm analyzed above was used and because subjects were evaluated as a part of a larger study unrelated to the present hypotheses.

Leisure activities. At the initial visit, an interview elicited self-reported participation during the month preceding the interview in the following 13 activities: knitting or music or other hobby, walking for pleasure or excursion, visiting friends or relatives, being visited by relatives or friends, physical conditioning, going to movies or restaurants or sporting events, reading magazines or newspapers or books, watching television or listening to the radio, doing unpaid community volunteer work, playing cards or games or bingo, going to a club or center, going to classes, and going to church or synagogue or temple. One point was given for participation to each of the above activities and an aggregate score was assigned to each patient for the subsequent analysis. Leisure activities were treated both as a continuous and as a discrete variable, using the median value for dichotomization (low was defined as $\leq 6$, and high was defined as $>6$ ). Leisure interview responses were not utilized for dementia diagnosis.

Statistical analysis. Analysis of variance (ANOVA), Student's $t$-test, $\chi^{2}$ analyses, and Pearson's correlation coefficient were used to examine the concordance of leisure activities with other potentially interactive variables, including ethnicity, gender, education, occupation, health limitations interfering with desired leisure activities, depression, heart disease, hypertension, diabetes, stroke, and baseline cognitive performance. Subjects were assigned into the three ethnic groups: white non-Hispanic, black non-Hispanic, and Hispanic. Education was treated both as a continuous (years of education) and a dichotomous variable (low, $\leq 8$ years; and high, $>8$ years]). Subjects' primary lifetime occupations were grouped into low (unskilled/semiskilled, skilled trade or craft, and clerical/office worker), high (manager business/government and professional/technical), and housewives (which were treated as a separate third category). Subjects were assigned into depression and nondepression groups by utilizing their answers to a questionnaire reflecting the DSM-III-R criteria for major depression. Depression was diagnosed if they fulfilled five out of 10 criteria (one of which required to be depressed mood or anhedonia). At the baseline visit, subjects reported whether they ever had a stroke confirmed by their physician, whether they ever had or were treated for hypertension or heart disease, and whether they received treatment for diabetes. They also reported any health limitations, problems or difficulties that interfered with desired social or leisure activities.

The initial Cox proportional hazards model $\mathrm{s}^{35}$ examined the association of leisure activities to the $R R$ of incident dementia. For dementia cases, we assigned onset as the age of the first follow-up visit at which dementia was documented. The subject's age was used as the time axis for the overall analyses. To adjust for possible cohort effects, the Cox analyses were stratified by age into three groups: 65 to 74,75 to 84 and $\geq 85$. Subsequent Cox models contained leisure activity and variables that qualified as potential confounders: ethnic group, education, and occupation.

Finally, we calculated the association between leisure activities and RR of incident dementia in a complete Cox model that included all covariates: ethnicity, education, occupation, health limitations interfering with desired leisure activities, depression, heart disease, hypertension, diabetes, and stroke.

The interaction between leisure activities and education was examined by dividing subjects into four groups: low leisure and low education, high leisure and low education, low leisure and high education, and high leisure and high education. The RR of dementia was calculated using the high-leisure and high-education group as the reference group. Interaction between leisure activities and occupation was evaluated using the same type of analysis.

The relative contribution of the individual items of the leisure activities to incident dementia was explored by calculating a Cox analysis for each item. The analyses were repeated with the items of leisure score grouped into three factors reflecting intellectual, physical, and social activities.

Supplementary analyses controlled for the effect of baseline cognitive function on incident dementia by including the total recall score from the Selective Reminding Test, as assessed during first visit.

In order to control for possible assessment bias, we also recalculated the relation of leisure activities to incident dementia when subjects with an initial diagnosis of borderline dementia (CDR $=0.5$ ) were eliminated, applying the above complete Cox model with all the covariates to the remaining set of subjects with $\mathrm{CDR}=0$.

Results. Subject accrual and follow-up. Of the 2,126 subjects, 327 were demented at first evaluation and were excluded from further analyses. From the remaining 1,799 subjects, leisure information was available for 1,772. At follow-up, 207 subjects were diagnosed with dementia: 153 subjects with probable or possible $\mathrm{AD}, 27$ with possible $\mathrm{AD}$ with concomitant stroke, eight with stroke-related dementia, and 19 with other dementia diagnoses. All subjects were retained in the primary analyses regardless of dementia subtype. Mean duration of follow-up was 2.9 (range 0 to 7.2) years. Demographic variables and frequencies of medical conditions of subjects who did and did not become demented are presented in table 1 . Table 2 presents mean leisure scores in various demographic and medical condition groups.

Cox models. When the leisure activities score was treated as a continuous variable in an age stratified Cox model, higher score were associated with a reduced risk of dementia. (RR, 0.88; 95\% CI, 0.83 to 0.93). Survival curves for incident dementia of high and low leisure activity subjects in the three age groups are presented in the figure.

Leisure activity had still a significant independent effect when ethnic group, education, and occupation were 
Table 1 Demographics in subjects who did and did not become demented

\begin{tabular}{lccc}
\hline Demographics & $\begin{array}{c}\text { Incident } \\
\text { dementia }\end{array}$ & $\begin{array}{c}\text { No } \\
\text { dementia }\end{array}$ & $\begin{array}{c}p \\
\text { Value }\end{array}$ \\
\hline No. of subjects & 207 & 1565 & \\
Age, y, \pm SD & $78.2 \pm 6.5$ & $75.3 \pm 6.2$ & $<0.001$ \\
Sex, \% women & 69 & 68 & $<0.94$ \\
Leisure, mean \pm SD & $5.7 \pm 2.6$ & $6.6 \pm 2.4$ & $<0.001$ \\
Leisure, high, \% & 37 & 52 & $<0.001$ \\
Education, y, mean \pm SD & $7.1 \pm 4.5$ & $8.7 \pm 4.5$ & $<0.001$ \\
Education, high, \% & 39 & 50 & $<0.01$ \\
Occupation, high, \% & 18 & 25 & $<0.05$ \\
Stroke, \% & 7 & 6 & $<0.84$ \\
Hypertension, \% & 59 & 59 & $<0.98$ \\
Heart disease, \% & 39 & 32 & $<0.05$ \\
Diabetes, \% & 16 & 13 & $<0.18$ \\
Depression, \% & 30 & 25 & $<0.06$ \\
\hline
\end{tabular}

included in the Cox model, with higher scores being associated with reduced risk of incident dementia (table 3 ).

When subjects were assigned to one of four leisure/ education and leisure/occupation groups respectively, risk of dementia was highest in the low-leisure/low-education (RR, 2.30; 95\% CI, 1.55 to 3.39 when compared to high leisure/high education) and low-leisure/low-occupation groups (RR, $1.86 ; 95 \% \mathrm{CI}, 1.16$ to 3 when compared to high-leisure/high-occupation). Based on the criteria described by Rothman, ${ }^{36}$ the effects of leisure and education and leisure and occupation meet criteria for statistical interaction (departure from risk difference additivity and risk ratio multiplicativity), suggesting a synergistic effect of leisure activities and education and leisure activities and occupation.

We further explored the relative contribution of the individual items of the leisure score to incident dementia by introducing them independently into Cox analyses along

Table 2 Mean leisure scores in various demographic and medical condition groups

\begin{tabular}{lcc}
\hline $\begin{array}{l}\text { Demographics and medical } \\
\text { conditions }\end{array}$ & $\begin{array}{c}\text { Mean leisure } \\
\text { scores }(0-13)\end{array}$ & $\begin{array}{c}p \\
\text { Value }\end{array}$ \\
\hline Female/male & $6.4 / 6.8$ & $<0.001$ \\
Hispanics/blacks/whites & $6.2 / 6.7 / 6.8$ & $<0.001$ \\
Education: low/high & $6.0 / 7.1$ & $<0.001$ \\
Occupation: housewifes/low/high & $6.2 / 6.3 / 7.3$ & $<0.001$ \\
Health-related disabilities: yes/no & $5.4 / 7.0$ & $<0.001$ \\
Depression: yes/no & $5.5 / 6.9$ & $<0.001$ \\
Heart disease: yes/no & $6.0 / 6.8$ & $<0.001$ \\
Hypertension: yes/no & $6.4 / 6.7$ & $<0.01$ \\
Diabetes: yes/no & $5.9 / 6.6$ & $<0.001$ \\
Stroke: yes/no & $5.1 / 6.6$ & $<0.001$ \\
\hline
\end{tabular}

For calculation of $p$ values, Student's $t$-test or analysis of variance have been used accordingly.
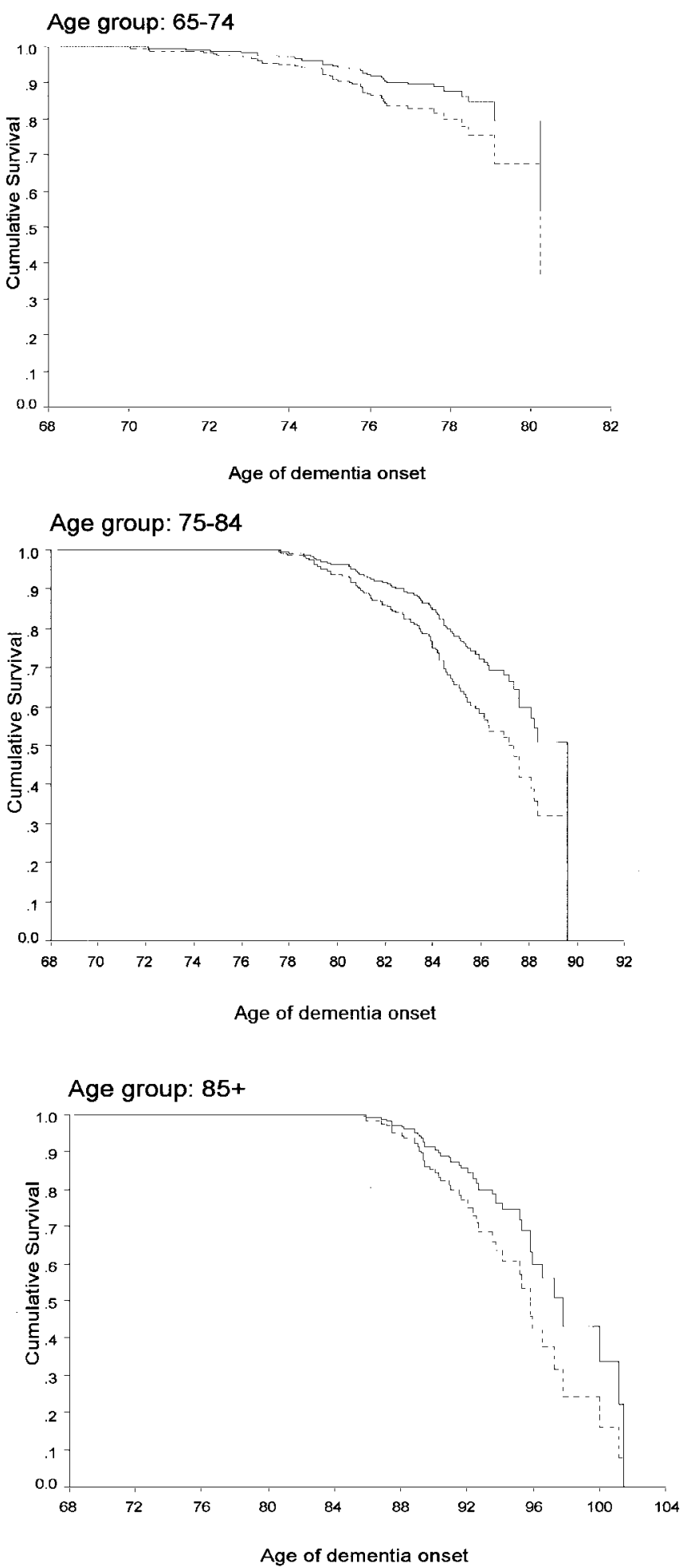

Figure. Survival curve based on Cox analysis comparing cumulative dementia incidence in subjects with high and low leisure activities in the three age groups. Solid line = high leisure group; dashed line = low leisure group.

with ethnic group, education, and occupation. The activities more strongly associated with reduced risk of incident dementia were reading magazines or newspapers (RR, 0.49 ; $95 \% \mathrm{CI}, 0.35$ to 0.68$)$, visiting friends or relatives (RR, $0.60 ; 95 \% \mathrm{CI}, 0.45$ to 0.80 ), going out to movies or restaurants (RR, 0.62;95\% CI, 0.44 to 0.86 ), and walking 
Table 3 Cox proportional hazard model predicting incident dementia by ethnic group, education, occupation, and leisure (controlling for age stratified at three age groups)

\begin{tabular}{lcc}
\hline & $\mathrm{RR}$ & $95 \% \mathrm{CI}$ \\
\hline $\begin{array}{l}\text { Ethnic group } \\
\quad \text { White vs black }\end{array}$ & 0.52 & $0.33-0.80$ \\
$\quad$ Hispanic vs black & 0.91 & $0.66-1.27$ \\
$\begin{array}{l}\text { Education } \\
\quad \text { High vs low }\end{array}$ & 0.81 & $0.58-1.12$ \\
$\begin{array}{l}\text { Occupation } \\
\quad \text { High vs low }\end{array}$ & & \\
$\quad \begin{array}{l}\text { Housewife vs low } \\
\text { Leisure }\end{array}$ & 0.86 & $0.58-1.28$ \\
$\quad$ Continuous variable & 0.95 & $0.66-1.35$ \\
$\quad$ High vs low & & $0.84-0.94$ \\
\hline
\end{tabular}

The relative risk (RR) for leisure as continuous variable reflects risk for each additional point of the leisure score.

for pleasure or going for an excursion (RR, 0.73; 95\% CI, 0.55 to 0.98 ). The analyses were repeated with the leisure items grouped into three continuous factors scores: intellectual (reading newspapers or magazines, playing cards or games or bingo, and going to classes), physical (walking for pleasure or going for an excursion and physical conditioning), and social (visiting or being visited by friends or relatives, going out to movies or restaurants or clubs or centers, doing voluntary community work, and going to church or synagogue). The intellectual factor was associated with the lowest RR of dementia (RR, 0.76; 95\% CI, 0.61 to 0.94$)$ but the relative risks associated with the physical (RR, 0.80;95\% CI, 0.66 to 0.97 ) and the social factors (RR, 0.85; 95\% CI, 0.77 to 0.94 ) also reached significance.

Supplementary analyses. Baseline cognitive performance. Subjects with better baseline cognitive perfor-

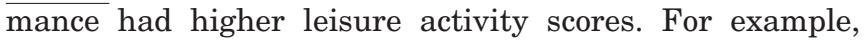
there was an association between leisure score and the total recall score of the Selective Reminding Test ( $r=0.27$; $p<0.001$ ). Similarly, leisure score correlated with the similarities adjusted score of the Weschler Adult Intelligence Scale III $(r=0.26 ; p<0.001)$. When we controlled for baseline cognitive profile in the Cox analyses, the results did not change. For example, when the total recall score from the Selective Reminding Test was introduced in a Cox model along with leisure as a continuous variable, ethnic group, education, and occupation, higher leisure was still associated with lower RR of incident dementia (RR, $0.89 ; 95 \% \mathrm{CI}, 0.82$ to 0.97 for leisure treated as a continuous variable).

Complete model. When ethnic group, education, occupation, health limitations interfering with desired leisure activities, depression, history of heart disease, hypertension, diabetes, or stroke were considered simultaneously in a Cox model, leisure activity had still a significant independent effect, with higher scores being associated with lower RR for incident dementia (RR, 0.90; 95\% CI, 0.84 to 0.96 for leisure treated as a continuous variable).

Assessment bias. We eliminated the subjects with an initial diagnosis of borderline dementia $(\mathrm{CDR}=0.5)$ and
1,478 subjects remained available for the analysis; 140 were subsequently diagnosed with incident dementia. In a complete Cox model that simultaneously considered the effect of leisure activity, ethnic group, education, occupation, health limitations interfering with desired leisure activities, depression, history of heart disease, hypertension, diabetes, or stroke in this subject group, the findings were essentially unchanged (RR, 0.92; 95\% CI, 0.85 to 0.99 for leisure treated as a continuous variable). Therefore, there was an $8 \%$ less risk of developing dementia for each added item of leisure activity endorsed.

Discussion. Our findings suggest a relation between the degree of leisure activity and the risk of developing $\mathrm{AD}$. Even when factors such as ethnic group, education, and occupation were controlled for, subjects with high leisure activity had 38\% less risk of developing dementia. The effect of leisure activities on incident dementia was still present even when baseline cognitive performance, health limitations interfering with social activities, cerebrovascular disease, and depression were considered.

Among leisure activities, reading, visiting friends or relatives, going to movies or restaurants, and walking for pleasure or going for an excursion were most strongly associated with a reduced risk of incident dementia. When the overall score was used in the Cox models, a protective effect for incident dementia was seen for each additional point, implying a cumulative effect for the number of activities adopted. When the leisure items were grouped into physical, social and intellectual factors, all three factors retained their significant effect although the intellectual factor was associated with lowest RR of incident dementia.

The cognitive reserve hypothesis suggests that aspects of life experience supply a set of skills or repertoires that allow an individual to cope with progressing $\mathrm{AD}$ pathology for a longer time before the disease becomes clinically apparent. However the concept of a reserve must be weighed against several alternative possibilities.

Health limitations, problems or difficulties can interfere with desired social or leisure activities as evidenced by their significant association. Vascular disease has been implicated in the clinical expression of $\mathrm{AD}$ pathology. ${ }^{37}$ Also reports of fewer social engagements could be partially related to underlying depressive illness, and the preexistence of depression may increase the likelihood of incident dementia. ${ }^{38-40}$ The association between leisure and incident dementia remained after inclusion in the analyses of covariates for all these potential confounders.

It can also be argued that low leisure activity may represent a manifestation of early dementia rather than a premorbid risk factor. The consequence of such a premise would be that subjects with borderline dementia might have lower leisure activity as a result of early disease. We therefore repeated our analyses after eliminating subjects with scores indicating borderline dementia $(\mathrm{CDR}=0.5)$ and repli- 
cated the findings seen in the complete cohort. Still, the possibility that low leisure activities reflect early disease consequences rather than a premorbid risk factor cannot be entirely excluded.

Maintaining intellectual and social engagement through participation in everyday activities seems to buffer healthy individuals against cognitive decline in later life. ${ }^{41-43}$ With regard to incident dementia, educational and occupational attainments have been extensively studied, but there are very few reports examining the influence of socially and intellectually engaged lifestyle to dementia. One case control study of $\mathrm{AD}$ in $\mathrm{Japan}^{44}$ (60 cases) reported that cases had less use of leisure time, hobbies, and psychosocial behaviors. Another case-control study examined the presence of intellectual, passive, and physical activities during midlife in 193 subjects with possible and probable AD. Diversity of activities and intensity of intellectual activities were reduced in patients with $\mathrm{AD}$ as compared with the control group. ${ }^{45}$

Only two prospective longitudinal studies have addressed the effect of social activities on incident dementia. In a survey sample of 422 elderly subjects, the relation of various indicators of socioeconomic status to incident dementia was investigated. ${ }^{14}$ Only poor quality of living accommodations was associated with increased RR of incident dementia, while indicators of social isolation and social support did not prove to be significant.

Another study evaluated social and leisure activity data in 2,040 nondemented elderly community residents from Gironde (France) and recorded incident dementia on follow-up visits. ${ }^{15}$ Traveling, doing odd jobs, and knitting were associated with lower risk of incident dementia when occupational status was controlled for. However, the analyses were not controlled for ethnic group, gender, educational attainment, cerebrovascular risk factors, or depressive symptomatology. In addition, for doing odd jobs and knitting, the effect was significant only when subjects who did the activities without difficulty were compared to subjects who did not do them because of deficiencies or disabilities. When the comparison group was subjects who were not engaged in these two activities for other reasons, no significant influence was noted. Therefore, the reasons for engaging in leisure activities, rather than the leisure activities per se, seemed to affect incident dementia in that study. In our study, medical problems interfering with desired leisure activities did not affect the association of leisure with dementia.

We also cannot dismiss the potential physiologic effects of leisure activities. Exposure to an enriched environment, defined as a combination of more opportunities for physical activity, learning, and social interaction, produces not only a host of structural and functional changes in the brain but also influences the rate of neurogenesis in adult and senescent animal models. ${ }^{46-48}$ Also, there is recent evidence that certain brain areas retain the capability to generate new neurons into adulthood, not only in rodents and primates, ${ }^{49}$ but also in humans. ${ }^{50}$ Although it may appear unlikely that aspects of life experience could impede the development of pathologic changes of $\mathrm{AD}$, it has been proposed that enhanced chronic neuronal activation associated with increased brain work, increased regional cerebral blood flow, and increased glucose and oxygen metabolism may be resulting in hindering the development of the disease. ${ }^{7}$ Engagement in social, intellectual, and physical activities could also promote a physiologic process involving increased synaptic density in neocortical association cortex, acquired on the basis of stimulation. ${ }^{9}$

There are physiologic data that have provided an indirect affirmation of the reserve hypothesis. Controlling for clinical severity of dementia, regional cerebral blood flow has been shown to be lower in patients with higher educational and occupational attainments. ${ }^{51,52}$ Similar results seem to emerge for leisure: an inverse association between leisure activities and regional cerebral blood flow, when controlling for disease severity, education, and IQ, has been demonstrated in $\mathrm{AD}$ patients. ${ }^{53}$

Despite the results of this study, the possibility that absence of social and intellectual engagements may not be risk factors themselves but may be related to some unknown causal risk factor cannot be completely excluded. In that case, leisure activities might be a surrogate marker for the actual risk factor. Further research is necessary to clarify the exact pathophysiologic changes that underlie the mechanisms of the reserve phenomenon. However, the observed epidemiologic associations suggest the possibility that interventions that enhance life experiences and activities might reduce the risk of developing dementia.

\section{Acknowledgment}

The authors thank Nicole Schupf, $\mathrm{PhD}$, for her thoughtful review of the manuscript.

\section{References}

1. Dartigues JF, Gagnon M, Michel P, et al. The Paquid research program on the epidemiology of dementia. Methods and initial results. Rev Neurol 1991;147:225-230.

2. Bonaiuto S, Rocca W, Lippi A. Impact of education and occupation on prevalence of Alzheimer's disease (AD) and multiinfarct dementia (MID) in Appignano, Macerata Province, Italy. Neurology 1990;40(suppl 1):346.

3. Zhang MY, Katzman R, Salmon D, et al. The prevalence of dementia and Alzheimer's disease in Shanghai, China: impact of age, gender, and education. Ann Neurol 1990;27:428-437.

4. Fratiglioni L, Grut M, Forsell Y, et al. Prevalence of Alzheimer's disease and other dementias in an elderly urban population: relationship with age, sex, and education. Neurology 1991;41:1886-1892.

5. Korczyn A, Kahana E, Galper Y. Epidemiology of dementia in Ashkelon, Israel. Neuroepidemiology 1991;10:100.

6. Sulkava R, Wikstrom J, Aromaa A, et al. Prevalence of severe dementia in Finland. Neurology 1985;35:1025-1029.

7. Friedland RP. Epidemiology, education, and the ecology of Alzheimer's disease. Neurology 1993;43:246-249.

8. Kittner SJ, White LR, Farmer ME, et al. Methodological issues in screening for dementia: the problem of education adjustment. J Chronic Dis 1986;39:163-170.

9. Katzman R. Education and the prevalence of dementia and Alzheimer's disease. Neurology 1993;43:13-20. 
10. Mortimer J. Do psychosocial risk factors contribute to Alzheimer's disease? In: Henderson AS, Henderson JH, eds. Etiology of dementia of Alzheimer's type. New York, NY: John Wiley \& Sons; 1988:39-52.

11. Gurland B. The borderlands of dementia: the influence of sociocultural characteristics on rates of dementia occurring in the senium. Aging 1981;15:61-84.

12. Satz P. Brain reserve capacity on symptom onset after brain injury: a formulation and review of evidence for threshold theory. Neuropsychology 1993;7:273-295.

13. Stern Y, Gurland B, Tatemichi TK, Tang MX, Wilder D, Mayeux R. Influence of education and occupation on the incidence of Alzheimer's disease. JAMA 1994;271:1004-1010.

14. Bickel H, Cooper B. Incidence and relative risk of dementia in an urban elderly population: findings of a prospective field study. Psychol Med 1994;24:179-192.

15. Fabrigoule C, Letenneur L, Dartigues JF, Zarrouk M, Commenges D, Barberger-Gateau P. Social and leisure activities and risk of dementia: a prospective longitudinal study. J Am Geriatr Soc 1995;43:485-490.

16. Gurland B, Golden RR, Teresi JA, Challop J. The SHORTCARE. An efficient instrument for the assessment of depression, dementia and disability. J Gerontol 1984;39:166-169.

17. Stern Y, Andrews H, Pittman J, et al. Diagnosis of dementia in a heterogeneous population. Development of a neuropsychological paradigm-based diagnosis of dementia and quantified correction for the effects of education. Arch Neurol 1992; 49:453-460.

18. Buschke H, Fuld PA. Evaluating storage, retention, and retrieval in disordered memory and learning. Neurology 1974; 24:1019-1025.

19. Benton A. The Visual Retention Test. New York, NY: The Psychological Corp; 1955.

20. Wechsler D. Wechler Adult Intelligence Scale, Revised. New York, NY: The Psychological Corp; 1981.

21. Mattis S. Mental Status examination for organic mental syndrome in the elderly patient In: Bellak L, Karasu TB, eds. Geriatric psychiatry. New York, NY: Grune \& Stratton; 1976.

22. Kaplan E, Goodglass H, Weintraub S. Boston Naming Test. Philadelphia, PA: Lea \& Febiger; 1983.

23. Benton A, Hamsher A. Multiligual Aphasia Examination. Iowa City: University of Iowa; 1976.

24. Goodglass H, Kaplan D. The assessment of aphasia and related disorders, 2nd ed. Philadelphia, PA: Lea \& Febiger; 1983.

25. Rosen W. The Rosen Drawing Test. Bronx, NY: Veterans Administration Medical Center; 1981.

26. Katzman R, Brown T, Fuld P, Peck A, Schechter R, Schimmel $\mathrm{H}$. Validation of a short Orientation-Memory-Concentration Test of cognitive impairment. Am J Psychiatry 1983;140:734739 .

27. Blessed G, Tomlinson BE, Roth M. The association between quantitative measures of dementia and of senile change in the cerebral grey matter of elderly subjects. Br J Psychiatry 1968; 114:797-811.

28. Schwab J, England A. Projection technique for evaluating surgery in Parkinson's disease In: Gillinghan FS, Donaldson MN, eds. Third Symposium on Parkinson's Disease. Edinburg, Scotland: E \& S Livingstone; 1969:152-157.

29. Spitzer R, Williams J. Structured clinical interview for DSM III-R-Hamilton version. New York: New York State Psychiatric Institute; 1986.

30. Hamilton M. A rating scale for depression. J Neurol Neurosurg Psychiatry 1960;23:56-62.

31. Williams JB. A structured interview guide for the Hamilton Depression Rating Scale. Arch Gen Psychiatry 1988;45:742747.

32. American Psychiatric Association CoNaS. Diagnostic and Statistical Manual of Mental Disorders, Revised Third Edition. Washington, DC: American Psychiatric Association; 1987.
33. McKhann G, Drachman D, Folstein M, Katzman R, Price D, Stadlan EM. Clinical diagnosis of Alzheimer's disease: report of the NINCDS-ADRDA Work Group under the auspices of Department of Health and Human Services Task Force on Alzheimer's Disease. Neurology 1984;34:939-944.

34. Hughes CP, Berg L, Danziger WL, Coben LA, Martin RL. A new clinical scale for the staging of dementia. Br J Psychiatry 1982;140:566-572.

35. Lawless J. Statistical model and methods for lifetime data. New York, NY: John Wiley \& Sons; 1982.

36. Rothman K. Modern epidemiology. Boston, MA: Little Brown \& Co; 1986:311-326.

37. Snowdon DA, Greiner LH, Mortimer JA, Riley KP, Greiner PA, Markesbery WR. Brain infarction and the clinical expression of Alzheimer disease. The Nun Study. JAMA 1997;277: 813-817.

38. Alexopoulos GS, Meyers BS, Young RC, Mattis S, Kakuma T. The course of geriatric depression with "reversible dementia": a controlled study. Am J Psychiatry 1993;150:1693-1699.

39. Bassuk SS, Berkman LF, Wypij D. Depressive symptomatology and incident cognitive decline in an elderly community sample. Arch Gen Psychiatry 1998;55:1073-1081.

40. Devanand DP, Sano M, Tang MX, et al. Depressed mood and the incidence of Alzheimer's disease in the elderly living in the community. Arch Gen Psychiatry 1996;53:175-182.

41. Hultsch DF, Hertzog C, Small BJ, Dixon RA. Use it or lose it: engaged lifestyle as a buffer of cognitive decline in aging? Psychol Aging 1999;14:245-263.

42. Gold DP, Andres D, Etezadi J, Arbuckle T, Schwartzman A, Chaikelson J. Structural equation model of intellectual change and continuity and predictors of intelligence in older men. Psychol Aging 1995;10:294-303.

43. Schaie K. Midlife influences upon intellectual functioning in old age. International J Behavioral Development 1984;7:463478.

44. Kondo K, Niino M, Shido K. A case-control study of Alzheimer's disease in Japan-significance of life-styles. Dementia 1994;5:314-326.

45. Friedland R, Fritsch T, Smyth K, et al. Patients with Alzheimer' disease have reduced activities in midlife compared with healthy control-group members. Proc Natl Acad Sci USA 2001;98:3440-3445.

46. Kempermann G, Kuhn HG, Gage FH. Genetic influence on neurogenesis in the dentate gyrus of adult mice. Proc Natl Acad Sci USA 1997;94:10409-10414.

47. Kempermann G, Kuhn HG, Gage FH. More hippocampal neurons in adult mice living in an enriched environment. Nature 1997;386:493-495.

48. van Praag H, Kempermann G, Gage FH. Running increases cell proliferation and neurogenesis in the adult mouse dentate gyrus. Nat Neurosci 1999;2:266-270.

49. Gould E, Reeves AJ, Graziano MS, Gross CG. Neurogenesis in the neocortex of adult primates. Science 1999;286:548-552.

50. Eriksson PS, Perfilieva E, Bjork-Eriksson T, et al. Neurogenesis in the adult human hippocampus. Nat Med 1998;4:13131317.

51. Stern Y, Alexander GE, Prohovnik I, Mayeux R. Inverse relationship between education and parietotemporal perfusion deficit in Alzheimer's disease. Ann Neurol 1992;32:371-375.

52. Stern Y, Alexander GE, Prohovnik I, et al. Relationship between lifetime occupation and parietal flow: implications for a reserve against Alzheimer's disease pathology. Neurology 1995;45:55-60.

53. Scarmeas N, Zarahn E, Anderson KE, et al. Association of leisure activities with regional cerebral blood flow (RCBF) in Alzheimer's disease ( $\mathrm{AD}$ ): implications for the cognitive reserve hypothesis. Presented at: the Society for Neuroscience 31st Annual Meeting; November 10-15, 2001; San Diego, CA. 


\title{
Neurology
}

\author{
Influence of leisure activity on the incidence of Alzheimer's Disease \\ N. Scarmeas, G. Levy, M.-X. Tang, et al. \\ Neurology 2001;57;2236-2242 \\ DOI 10.1212/WNL.57.12.2236
}

This information is current as of December 26, 2001

\section{Updated Information \& Services}

\section{References}

Citations

Subspecialty Collections

Permissions \& Licensing

Reprints including high resolution figures, can be found at: http://www.neurology.org/content/57/12/2236.full.html

This article cites 32 articles, 13 of which you can access for free at: http://www.neurology.org/content/57/12/2236.full.html\#\#ref-list-1

This article has been cited by 57 HighWire-hosted articles: http://www.neurology.org/content/57/12/2236.full.html\#\#otherarticles

This article, along with others on similar topics, appears in the following collection(s):

Alzheimer's disease

http://www.neurology.org//cgi/collection/alzheimers_disease Incidence studies

http://www.neurology.org//cgi/collection/incidence_studies

Information about reproducing this article in parts (figures,tables) or in its entirety can be found online at:

http://www.neurology.org/misc/about.xhtml\#permissions

Information about ordering reprints can be found online:

http://www.neurology.org/misc/addir.xhtml\#reprintsus

Neurology ${ }^{\circledR}$ is the official journal of the American Academy of Neurology. Published continuously since 1951, it is now a weekly with 48 issues per year. Copyright . All rights reserved. Print ISSN: 0028-3878.

Online ISSN: 1526-632X.

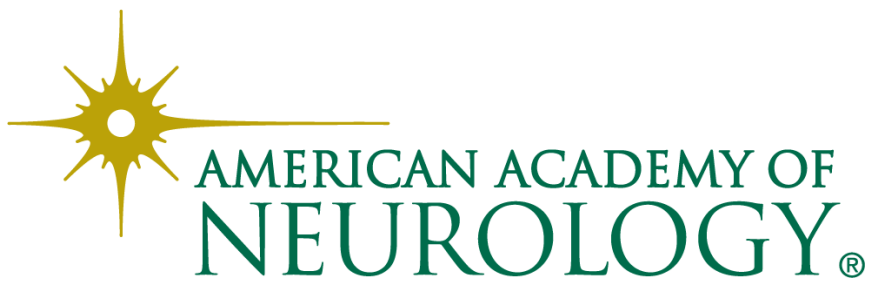

